\title{
Relative value of repeat gastric ulcer surveillance gastroscopy in diagnosing gastric cancer
}

\author{
A. Neil Hopper ${ }^{1}$, Michael R. Stephens ${ }^{1}$, Wyn G. Lewis ${ }^{1}$, Guy R.J.C. Blackshaw ${ }^{1}$, Matthew A. Morgan, ${ }^{2}$ \\ IAn Thompson ${ }^{3}$, and Miles C. Allison ${ }^{4}$ \\ ${ }^{1}$ Department of Surgery, University Hospital of Wales, Cardiff, Cardiff and Vale NHS Trust, Heath Park, Cardiff, CF14 4XN, UK \\ ${ }^{2}$ Department of Surgery, Royal Gwent Hospital, Newport, UK \\ ${ }^{3}$ Department of Histopathology, Royal Gwent Hospital, Newport, UK \\ ${ }^{4}$ Department of Gastroenterology, Royal Gwent Hospital, Newport, UK
}

\begin{abstract}
Background. Gastric cancer can present with the endoscopic appearances of a benign gastric ulcer (GU). Opinion remains divided on the need for follow-up of patients diagnosed with $G U$, and the aim of this study was to examine the long-term outcomes of patients whose GU proved malignant on followup gastroscopy.

Methods. Between October 1, 1995, and September 30, 2003, 25579 gastroscopies were performed in one unit. These identified 544 patients with apparently benign GU, of whom 277 (51\%) underwent 334 elective follow-up endoscopies. Twelve of these patients $(4.3 \%)$ were shown to have a malignant ulcer; their outcomes were compared to those of the 296 other patients diagnosed with gastric cancers in this time frame.

Results. The patients in the $\mathrm{GU}$ cancer group had earlier stage disease (stage I, 33\% vs $6.4 \% ; \chi^{2}=11.2 ;$ DF1; $P=0.001$ ), and were more likely to undergo R0 gastrectomy (50\% vs $30 \% ; \chi^{2}$ $=2.064 ; D F 1 ; P=0.151)$ and to survive long term $(46 \%$ vs $16 \%$; log-rank $\left.\chi^{2}, 5.79 ; D F 1 ; P=0.0162\right)$ than patients in the comparison cohort.

Conclusion. Gastroscopic follow-up of 50 patients with an apparently benign GU will identify 1 patient with a malignancy destined to survive for 5 years following $\mathrm{RO}$ gastrectomy. This justifies the diagnostic effort of repeat gastroscopy to ensure complete healing of $\mathbf{G U}$.
\end{abstract}

Key words Gastric ulcer · Gastric cancer · Gastroscopy

Offprint requests to: W.G. Lewis

Presented at: The British Society of Gastroenterology, Birmingham, 2005; The Association of Surgeons of Great Britain and Ireland, Glasgow, 2005; The 6th International Gastric Cancer Congress, Yokohama, 2005.

Received: January 23, 2006 / Accepted: May 17, 2006

\section{Introduction}

Gastric cancer can present with the endoscopic appearances of a benign gastric ulcer (GU), and superficial mucosal biopsy often fails to detect deeper malignant infiltration [1]. For these reasons traditional guidance recommends that all gastric ulcers should be followed with repeated endoscopy to ensure ulcer healing on treatment [2-5]. Certainly, the British Society of Gastroenterology currently recommends a policy of follow-up esophago-gastro-duodenoscopy (EGD) with biopsy for benign GU until the ulcer has healed completely [6].

Early diagnosis, including open access gastroscopy, has been heralded as the key to diagnosing patients with gastric cancer at a potentially curable stage $[7,8]$, and the development and widespread use of endoscopy, biopsy and histology has enhanced our ability to make the diagnosis of gastric cancer. Opinion remains divided, however, on the need for endoscopic follow-up for GU with no endoscopic or histological features of malignancy at the index EGD. Indeed, several recent reports have questioned the value of this practice because of the low diagnostic yield of repeat endoscopy [9-11]. Moreover, the strategy of endoscopic surveillance has not been shown to improve survival [12].

The aims of this study were (a) to examine the outcome of our policy of follow-up endoscopy for apparently benign GU, (b) to determine the diagnostic yield of gastric cancer in such patients, and (c) to compare their outcomes with those of all patients diagnosed with gastric cancers during the same period of time at our hospital. Akin to the concept of numbers of patients needed to treat (NNT) in therapeutic pharmacology, we also aimed to determine the numbers of patients needed to endoscope (NNE), i.e., the number of patients requiring GU surveillance endoscopy in order to identify a single patient with a malignant GU surviving to 5 years. 
Table 1. Patient characteristics

\begin{tabular}{lcc}
\hline Characteristic & $\begin{array}{c}\text { GU cancer group } \\
(n=12)\end{array}$ & $\begin{array}{c}\text { Comparison group } \\
(n=296)\end{array}$ \\
\hline Age, years (range) & $69(57-83)^{\mathrm{a}}$ & $71(27-100)^{\mathrm{a}}$ \\
Sex (male:female) & $1: 1$ & $1.9: 1$ \\
Stage of cancer (\%) & $4(33.3)$ & $19(6.4)^{\mathrm{b}}$ \\
I & $1(8.3)$ & $34(11.5)$ \\
II & $1(8.3)$ & $41(13.9)$ \\
IIIa & $1(8.3)$ & $27(9.1)$ \\
IIIb & $5(41.7)$ & $175(59.1)$ \\
IV &
\end{tabular}

Figures are numbers of patients, with percentages in parentheses

${ }^{a}$ Median years

${ }^{\mathrm{b}} \chi^{2}=11.2$, DF1, $P=0.001$

\section{Patients and methods}

\section{GU cancer group}

Between October 1, 1995, and September 30, 2003, 25579 EGDs were performed at the Royal Gwent Hospital for all indications. Five hundred and forty-four $(2.1 \%)$ patients were diagnosed with at least one apparently benign GU $3 \mathrm{~mm}$ or more in diameter. The hospital policy was to routinely follow-up patients diagnosed with single ulcers or multiple ulcers with any suspicious features. Patients with comorbidities precluding any surgical intervention, or patients of advanced age were not followed-up; neither were those with ulcers precipitated by nonsteroidal anti-inflammatory drugs (NSAIDs) or other known or suspected etiologies. Of the 544 patients, 277 (51\%) underwent at least one elective repeat EGD to monitor ulcer healing. The median interval between the index EGD and the first repeat EGD was 8 weeks. The timing of the repeat EGD varied according to the size of the ulcer, with patients with larger ulcers given a longer interval to allow the ulcer to heal. Two hundred and sixty-seven patients did not undergo a repeat elective EGD. The median age of these patients was 80 years (range, 10 to 101 years), compared with 64 years (range, 25 to 87 years) in patients who underwent surveillance EGD $(P<0.0001)$. Twentythree patients had unplanned repeat EGDs. As far as we are aware, none of these 267 patients have subsequently been diagnosed with gastric cancer in SouthEast Wales.

As a result of this process, 12 patients (median age 69 years; range, 57 to 83 years; 6 male) were diagnosed with gastric cancer. All of these patients had a lesion that had previously been described as benignappearing, and all had biopsies that were reported on histological examination to be negative for malignancy at their first EGD. One patient was deemed to have severe dysplasia and another had cellular atypia in association with active chronic inflammation. Both biopsies were reported as showing no evidence of malignancy; however, the reporting pathologist recommended that repeat EGD be undertaken. These biopsies were reviewed as part of this study and again were found to show no evidence of malignancy. Biopsies from the other 10 patients showed active chronic inflammation. All 12 patients were commenced on therapeutic doses of a proton-pump inhibitor following their index EGD (omeprazole, $20 \mathrm{mg}$, twice daily; AstraZeneca, London, UK). Four of the 12 patients were positive for Helicobacter pylori and received H. pylori eradication therapy (Heliclear [lansoprazole $30 \mathrm{mg}$, amoxicillin $500 \mathrm{mg}$, clarithromycin $500 \mathrm{mg}$ ] twice daily for 1 week; Wyeth, Madison, NJ, USA).

\section{Comparison group}

The details of all patients presenting to the Royal Gwent Hospital with gastric cancer have been collected prospectively since October 1995. The demographic details and stage of presentation of the patients diagnosed as having malignant ulcers by means of repeat EGD (GU cancer group) were examined in comparison with the 296 other patients found to have gastric cancer at the Royal Gwent Hospital in the same time frame (comparison group - see Table 1). The time to diagnosis was measured from the date when the patient first experienced symptoms (according to their own recollection) to the establishment of a histological diagnosis of malignancy. The overall delay (in weeks) was recorded for each patient and divided into five periods: (1) time from onset of symptoms to first consultation with general practitioner, (2) time from first consultation to referral to hospital, (3) time from referral to attendance at hospital for investigation or specialist consultation, (4) time from first attendance at hospital to diagnosis, and (5), for patients who had surgery, we also recorded the subsequent time to the date of their operation. Ethical approval was granted by the Gwent Research Ethics Committee. 
Table 2. Diagnostic delays

\begin{tabular}{|c|c|c|c|}
\hline Delay, in weeks, median (range) & GU cancer group & Comparison cohort & $P$ (where significant) \\
\hline Symptoms to first presentation at GP surgery & $11(1-104)$ & $12(1-156)$ & \\
\hline First presentation to referral & $2(1-6)$ & $1(<1-128)$ & \\
\hline Referral to hospital consultation & $3(<1-4)$ & $1(<1-10)$ & \\
\hline Hospital consultation to diagnosis & $10(1-66)$ & $2(<1-87)$ & 0.004 \\
\hline Diagnosis to surgery & $3(1-5)$ & $3(<1-9)$ & \\
\hline Symptoms to diagnosis & $35(12-175)$ & $20(1-173)$ & 0.041 \\
\hline Symptoms to surgery & $64(21-185)$ & $25(2-177)$ & 0.029 \\
\hline
\end{tabular}

GP, general practitioner (family physician)

Table 3. Details of the surgery

\begin{tabular}{lcc}
\hline & GU cancer group & Comparison cohort \\
\hline R0 gastrectomy & $6(50 \%)$ & $90(30 \%)$ \\
Palliative gastrectomy & 0 & $23(8 \%)$ \\
Palliative gastrojejunostomy & 0 & $9(3 \%)$ \\
Laparotomy only & $1(8 \%)$ & $27(9 \%)$ \\
Laparoscopy only & $4(33 \%)$ & $136(46 \%)$ \\
No surgery & $5(42 \%)$ & $147(50 \%)$ \\
\hline
\end{tabular}

\section{Staging and surgical treatment}

Among the 308 patients presenting with gastric cancer during the 8 years, 96 (31\%) underwent potentially curative surgical resection. All surgery was performed by one consultant upper GI surgeon (WGL), whose policy is to perform a modified D2 resection with extended lymphadenectomy, preserving pancreas and spleen where possible [7,13-15]. All tumors were staged initially in accordance with the 1987 Unified TNM classification of gastric cancer [16], and thereafter with the 1997 Unified TNM classification [17]. Staging included routine computed tomography of the thorax and abdomen, and preoperative laparoscopy for potential surgical candidates. No patient underwent neoadjuvant chemotherapy.

\section{Follow-up}

Patients undergoing surgery were reviewed every 3 months for the first year and 6-monthly thereafter. Two hundred and sixty-nine patients $(87 \%)$ were followedup for a minimum of 5 years or until death. Thirty-nine patients remain under follow-up. One of the 308 patients was lost to follow-up. The death certificates of all deceased patients were obtained from the Office of National Statistics (ONS).

\section{Statistical analysis}

Statistical analysis appropriate for nonparametric data was used [18]. Grouped data were expressed as medians (ranges). Cumulative survival was calculated by the lifetable method of Kaplan and Meier [19]. Differences in survival times between groups of patients were analyzed by the log-rank method [20,21]. The number of repeat EGDs required to identify a patient with a GU cancer destined to survive for 5 years was calculated using the following formula:

Number of repeat OGDs performed

Number of GU cancer patients $\times$ 5-year survival \%

Data were analyzed using the Statistical Package for Social Sciences (SPSS) version 12.0 for Windows (Chicago, IL, USA).

\section{Results}

\section{Diagnostic delay (Table 2)}

Three patients (25\%) in the GU cancer group presented acutely with emergency complications of their tumors, compared with 116 patients $(39 \%)$ in the comparison group $\left(\chi^{2}=2.064\right.$; DF1; $\left.P=0.322\right)$. For patients that presented conventionally (via outpatients or open access endoscopy) the median delay from onset of symptoms to a definitive diagnosis was 35 weeks in the GU cancer group compared to 20 weeks in the comparison group $(P=0.011)$. In patients undergoing surgery, the delay was significantly longer from diagnosis to operation in the GU cancer group than in the comparison group (64 vs 25 weeks; $P=0.022$ ). 
Table 4. Univariate analysis of factors associated with duration of survival

\begin{tabular}{lrrrrr} 
& \multicolumn{2}{c}{ All cases } & & \multicolumn{2}{c}{ GU cancer group } \\
\cline { 2 - 3 } Factor & Log rank & $P$ value & & Log rank & $P$ value \\
\hline Surveillance EGD & 5.79 & 0.0162 & & - & - \\
Sex & 1.43 & 0.2323 & & 6.03 & 0.0140 \\
Site of tumor & 32.99 & 0.00001 & & 11.41 & 0.0097 \\
Age & & & & \\
$\quad>50$ Years & 0.95 & 0.3306 & & - & 0.495 \\
$\quad>60$ Years & 3.21 & 0.0732 & & 0.47 & 0.1699 \\
$\quad>70$ Years & 4.00 & 0.0455 & & 1.88 & 0.9049 \\
$\quad>80$ Years & 3.71 & 0.0542 & & 0.01 & 0.175 \\
ASA grade & 24.11 & 0.00001 & & 8.09 & 0.5819 \\
T stage & 46.31 & 0.00001 & & 1.08 & 0.0581 \\
N stage & 86.93 & 0.00001 & & 5.69 & 0.1141 \\
M stage & 88.69 & 0.00001 & & 2.50 & 0.2109 \\
Overall stage of cancer & 100.56 & 0.00001 & & 5.85 & 0.0679 \\
R0 gastrectomy & 132.09 & 0.00001 & & 3.33 & \\
\hline
\end{tabular}

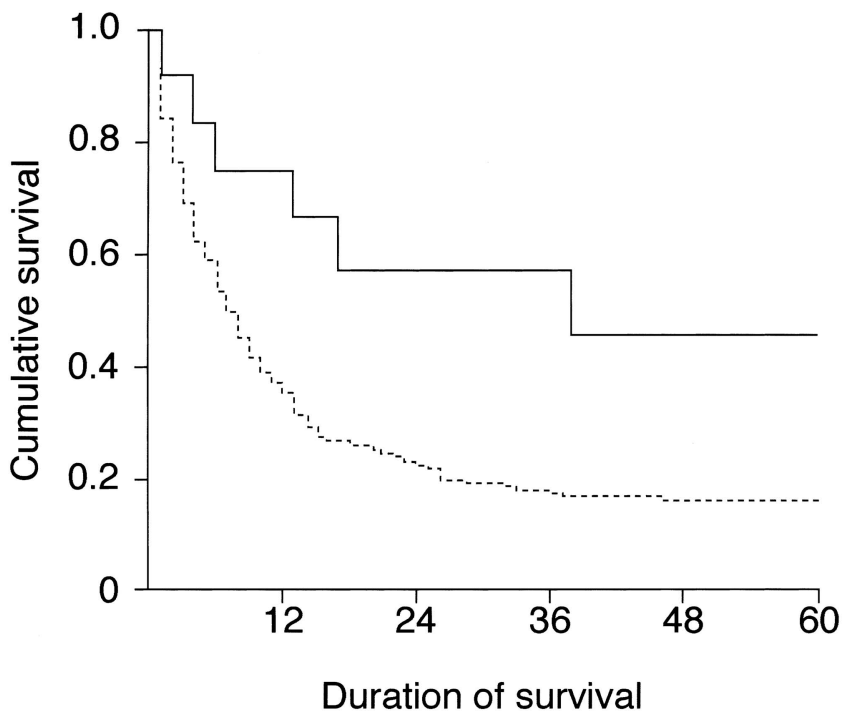

Fig. 1. Cumulative survival for patients diagnosed with gastric cancer on repeat esophago-gastro-duodenoscopy (EGD) vs controls. Continuous line, gastric ulcer group; dashed line, comparison cohort. Log-rank $\chi^{2}=5.79$; DF1; $P=0.0162$

Numbers at risk

\begin{tabular}{lrrrrrr}
\hline & \multicolumn{5}{c}{ Time from diagnosis (months) } \\
\cline { 2 - 7 } & 0 & 12 & 24 & 36 & 48 & 60 \\
\hline GU group & 12 & 8 & 5 & 4 & 2 & 1 \\
Comparison group & 296 & 104 & 53 & 33 & 22 & 17 \\
\hline
\end{tabular}

\section{Stage of disease at presentation}

The GU cancer group had significantly earlier stage disease at presentation than the comparison group, with $33 \%$ of the former being diagnosed with stage I gastric cancer as opposed to $6.4 \%$ of the latter $\left(\chi^{2}=11.2\right.$; DF1; $P=0.001)$. Five patients $(42 \%)$ in the surveillance group had early gastric cancer (EGC, T1/2, any N, M0) compared with $53(18 \%)$ in the comparison group $\left(\chi^{2}=4.26\right.$; $\mathrm{DF} 1 ; P=0.039)$.

\section{Details of the surgery performed}

Table 3 shows the surgical operations performed. Six $(50 \%)$ of the GU cancer group underwent a potentially curative R0 gastrectomy, compared with $90(30 \%)$ of the comparison cohort $\left(\chi^{2}=2.064\right.$; DF1; $P=0.151)$.

\section{Operative mortality and morbidity}

There was no significant operative morbidity recorded in the GU cancer group, compared with $27 \%$ of patients in the comparison group $\left(\chi^{2}=2.613\right.$; DF1; $\left.P=0.106\right)$. There was no operative mortality within 30 days of R0 gastrectomy in the GU cancer group, compared with $6.7 \%(6 / 90$ patients $)$ in the comparison cohort $\left(\chi^{2}=\right.$ 0.794; DF1; $P=0.373)$.

\section{Survival}

Uncorrected cumulative survival, calculated by life table analysis, is shown in Fig. 1. Median survival for the GU cancer group was 38 months (range, 1-68 months), with a cumulative survival of $46 \%$ at 5 years. In contrast, the median survival for the comparison cohort was 7 months (range, 1-104 months), with a cumulative survival of $16 \%$ at 5 years (Log-rank $\chi^{2}=5.79$; DF1; $P=$ 0.0162 ). The factors found to be significantly associated with the duration of survival on univariate analysis are shown in Table 4. 


\section{Multivariate analysis}

The prognostic variables entered into the model were age, sex, the American Society of Anesthesiology (ASA) grade, whether the tumor was diagnosed at surveillance EGD, stage of the tumor, anatomical location of the tumor, and R0 gastrectomy or not. Forward and backward stepwise regression was used. Overall stage of disease (hazard ratio, 1.601; 95\% CI, 1.325-1.934; $P=$ 0.0001 ), age over 70 years (hazard ratio, $1.406 ; 95 \% \mathrm{CI}$, $1.032-1.917 ; P=0.031$ ), and R0 gastrectomy (hazard ratio, $0.222 ; 95 \% \mathrm{CI}, 0.147-0.336 ; P=0.0001$ ) were found to be the most important predictors of outcome as determined by Cox's proportional hazards model (global $\chi^{2}$ for the model was 120.859 ; DF3; $P=0.0001$ ).

\section{Number of patients needed to endoscope (NNE)}

$$
\begin{aligned}
\mathrm{NNE} & =\frac{277}{12 \times 46 \%} \\
& =50 \text { surveillance EGDs per survivor at } 5 \text { years. }
\end{aligned}
$$

\section{Discussion}

The principal finding of this study was that repeat EGD to monitor the healing of apparently benign gastric ulcers detected potentially curable gastric cancer. Patients diagnosed with gastric cancer via repeat EGD for GU healing had earlier stage disease than the patients in the comparison group, and, moreover, despite longer diagnostic delays, were more likely to undergo R0 gastrectomy than patients in the comparison group. Furthermore, long-term survival was three times more likely in the GU cancer group of patients than in the comparison cohort of patients.

There are several potential sources of survival bias in this observational study that may influence the interpretation of the results [8]. One is lead-time bias, in which the date of the diagnosis is brought forward as the cancer is detected sooner. Apart from patients that presented with emergency complications of their tumors, the patients in this study had sought prior medical attention via their GPs before hospital referral, and the detection date of the cancer was not brought forward by investigation, and, hence, the survival of the GU cancer patients was not artificially lengthened. Referral bias does not apply to this study, as both cohorts of patients were referred and diagnosed via identical pathways. Length bias may apply to this study, because the initial benign appearance of the gastric ulcers, both endoscopically and histologically, at the index EGD suggests that the cancers detected by surveillance gastroscopy were inherently less aggressive and less likely to metastasize than other gastric cancer phenotypes.
Throughout the time period of the study it was the policy of the endoscopy unit to recommend repeat EGD to all patients diagnosed with an apparently benign gastric ulcer. This was not done for nearly half the patients, either because the endoscopist felt confident that the ulceration was benign (e.g., multiple small ulcers in a patient on NSAIDs), or because the patients were at the extremes of age and/or infirm and not potential surgical candidates. Some patients failed to attend for a repeat procedure. This selection may indeed explain our higher yield of cancers when compared to other published series [4,5,9-12] and the surprising finding that, as far as we are aware, none of those patients with a benign GU that did not undergo a repeat EGD went on to develop a malignancy. A comprehensive database of patients diagnosed with gastric cancer is maintained by the South-East Wales Multidisciplinary Cancer Network and it is, therefore, unlikely that any of these patients had a gastric cancer diagnosed within South-East Wales without our knowledge. Although our catchment population is relatively stable, there remains the small possibility that patients may have been diagnosed with gastric cancer without our knowledge outside our area of surveillance.

This study has several strengths. Data were collected prospectively for a consecutive group of unselected patients from a well-defined geographical area. All EGDs were conducted in the same hospital and all of the surgical group had their operations undertaken by a single consultant surgeon, whose results were comparable with those of the best Japanese and European centers [13-15]. The prognostic data are especially robust, with over $85 \%$ of patients followed-up for at least 5 years or until death, and only one patient lost to follow up. Moreover, durations of survival were determined by direct examination of death certificates.

The current practice of follow-up EGD for apparently benign GU seems to have evolved without a clear evidence base. Our study has demonstrated that 50 patients with an apparently benign GU need to undergo repeat EGD in order to in order to identify 1 gastric cancer patient who will survive for 5 years. We believe that this diagnostic yield justifies a policy of repeat EGD to ensure complete healing of GU, at least in patients who would be potential surgical candidates were malignancy to be identified.

\section{References}

1. Rollag A, Jacobsen CD. Gastric ulcer and risk of cancer. A 5-year follow-up study. Acta Med Scand 1984;216:105-9.

2. Sakita T, Oguro Y, Takasu S, Fukutomi H, Miwa T. Observations on the healing of ulcerations in early gastric cancer. The life cycle of the malignant ulcer. Gastroenterology 1971;60:835-9.

3. Paulino F, Roselli A. Early gastric cancer: report of 25 cases. Surgery 1979;85:171-6. 
4. Mountford RA, Brown P, Salmon PR, Alvarenga C, Neumann CS, Read AE. Gastric cancer detection in gastric ulcer disease. Gut 1980;21:9-17.

5. Lupano F, Sategna-Guidetti C. Endoscopic follow-up of patients with gastric ulcer. A prospective study. J Clin Gastroenterol 1986; 8:430-4.

6. British Society of Gastroenterology. Dyspepsia management guidelines (online). British Society of Gastroenterology; 2004. www.nice.org.uk/page.aspx?O=CGO17NICEguideline

7. Sue-Ling HM, Johnston D, Martin IG, Dixon MF, Lansdown MR, McMahon MJ, et al. Gastric cancer: a curable disease in Britain. BMJ 1993;307:591-6.

8. Blackshaw GR, Barry JD, Edwards P, Allison MC, Lewis WG. Open-access gastroscopy is associated with improved outcomes in gastric cancer. Eur J Gastroenterol Hepatol 2003;15:1333-7.

9. Card TR, Gorard DA, McIntyre AS. The role of follow-up endoscopy (EGD) for gastric ulcers (abstract). Gut 2005;53[suppl iii]:A8.

10. Tragardh B, Haglund U. Endoscopic diagnosis of gastric ulcer. Evaluation of the benefits of endoscopic follow-up observation for malignancy. Acta Chir Scand 1985;151:37-41.

11. Bustamante M, Devesa F, Borghol A, Ortuno J, Ferrando MJ. Accuracy of the initial endoscopic diagnosis in the discrimination of gastric ulcers: is endoscopic follow-up study always needed? J Clin Gastroenterol 2002;35:25-8.

12. Eckardt VF, Giessler W, Kanzler G, Bernhard G. Does endoscopic follow-up improve the outcome of patients with benign gastric ulcers and gastric cancer? Cancer 1992;69:301-5.
13. Lewis WG, Edwards P, Barry JD, Khan S, Dhariwal D, Hodzovic I, et al. D2 or not D2? The gastrectomy question. Gastric Cancer 2002;5:29-34.

14. Edwards P, Blackshaw GR, Lewis WG, Barry JD, Allison MC, Jones DR. Prospective comparison of D1 vs modified D2 gastrectomy for carcinoma. Br J Cancer 2004;90:1888-92.

15. Barry JD, Blackshaw GR, Edwards P, Lewis WG, Murphy P, Hodzovic I, et al. Western body mass indices need not compromise outcomes after modified D2 gastrectomy for carcinoma. Gastric Cancer 2003;6:80-5.

16. Kennedy B. The unified international gastric cancer staging classification. Scand J Gastroenterol 1987;22:11-13.

17. UICC TNM classification of malignant tumors. New York: John Wiley and Sons; 1997.

18. Altman D. Practical statistics for medical research. London: Chapman and Hall; 1991.

19. Kaplan E, Meier P. Non-parametric estimation from incomplete observations. J Am Stat Assoc 1958;58:457-81.

20. Peto R, Pike MC, Armitage P, Breslow NE, Cox DR, Howard SV, et al. Design and analysis of randomized clinical trials requiring prolonged observation of each patient. II. Analysis and examples. Br J Cancer 1977;35:1-39.

21. Peto R, Pike MC, Armitage P, Breslow NE, Cox DR, Howard SV, et al. Design and analysis of randomized clinical trials requiring prolonged observation of each patient. I. Introduction and design. Br J Cancer 1976;34:585-612. 